\title{
A Study of Complications of Poisonous Snake Bites
}

\author{
Sandip Ashok Mohale ${ }^{1}$, Anuj Ramesh Varma², Gopikishan Ramkishan Bharadiya ${ }^{3}$, \\ Sourya Acharya ${ }^{4}$, Shilpa Abhay Bawankule ${ }^{5}$ \\ 1, 2, 4,5 Department of Medicine, Jawaharlal Nehru Medical College, DMIMS (Deemed to \\ Be University), Sawangi (Meghe), Wardha, Maharashtra, India. ${ }^{3}$ Department of \\ Physician, Vivekanand Hospital and Research Centre, Latur, Maharashtra, India.
}

\section{ABSTRACT}

\section{BACKGROUND}

The present study was taken up to study the clinical manifestations, complications, and outcome in patients with poisonous snake bites admitted to Vivekanand Hospital, Latur (Maharashtra).

\section{METHODS}

This was a longitudinal study. Adult snakebite patients admitted from December 2012 to November 2014 were studied.

\section{RESULTS}

Mostly males (71.4\%) in the age group 18 - 29 years (58.6\%) were affected. Farmers $(71.4 \%)$ in rural areas $(87.1 \%)$ are the major sufferers. The neurotoxic venom poisoning ptosis (100\%) was commonest manifestation and was found in all cases. Palatal and pharyngeal palsy, ophthalmoplegia, respiratory palsy were also seen. In hemotoxic poisoning, bleeding from the bite site $(73 \%)$ was the commonest manifestation followed by hematuria (48.6 \%) and gum bleeding $(24.3$ $\%)$. Among complications of poisonous snakebites, cellulitis (86.5\%) was the most common followed by acute renal failure (47.6\%), disseminated intravascular coagulation (DIC) (23.8\%), respiratory paralysis (12.7\%) and shock (4.28\%).

Adverse reactions to anti-snake venom (ASV) were noted in $16(22.9 \%)$ patients. Total 10 patients died (14.3\%) mostly were due to acute renal failure (26.6\%).

\section{CONCLUSIONS}

Snakebite is common among agricultural labourers. Mostly males in the age group 18 - 29 years were bitten during 12 noon to $6 \mathrm{pm}$. Peak incidence peaked in between May to October. Viper bites were more common than Elapidae in this study. In neurotoxic envenomation, ptosis was the commonest and earliest symptom while in hemotoxic envenomation, most common symptoms were bleeding from bite site and hematuria. The commonest complications were cellulitis, acute renal failure and DIC. Early hospitalization and timely ASV were the corner stone in the treatment of snakebite.

\section{KEY WORDS}

Snakebite, Neurotoxic, Elapidae, Viperidae
Corresponding Author:

Dr. Anuj Ramesh Varma,

Department of Medicine,

Jawaharlal Nehru Medical College, DMIMS (Deemed to Be University),

Sawangi (Meghe), Wardha, Maharashtra, India.

E-mail: anujvarma1985@gmail.com

DOI: $10.14260 /$ jemds/2021/533

How to Cite This Article:

Mohale SA, Varma RA, Bharadiya RG, et al. a study of complications of poisonous snake bites. J Evolution Med Dent Sci 2021;10(32):2602-2608, $10.14260 /$ jemds/2021/533 DOI:

Submission 29-12-2020,

Peer Review 09-03-2021,

Acceptance 16-03-2021,

Published 09-08-2021.

Copyright (C) 2021 Sandip Ashok Mohale et al. This is an open access article distributed under Creative Commons Attribution License [Attribution 4.0 International (CC $B Y 4.0)]$ 


\section{BACKGROUND}

Snake bite is a preventable public hazard in a country like India which abounds with dense vegetations and vast tracts of agricultural land. India has always been known as 'a land of exotic snakes.' The snake bites a man or large animals only for the self defense. Venom in their saliva is for killing or paralyzing their prey. There are about 3000 species of snakes on the earth. In India there are about 9 families having 216 species of snakes and out of which 52 species belonging to 3 families are poisonous i.e., their bite may cause some toxic symptoms in man.1,2 In Marathwada region of Maharashtra, Russell's viper, cobra and common krait are the commonly found poisonous snakes. Snake bite is a common and frequently devastating environmental and occupational disease. Snake bites are a major problem in India especially in rural areas among the farming community. The million-death study estimated that approximately 50,000 people die of snake bite every year in India indicating a major public health problem. ${ }^{3}$ The enormous number of snake bites and deaths due to them prompted us to do this study.

There are five standard clinical syndromes -

1. Local envenoming (swelling etc.) with bleeding/clotting disturbances (Viperidae),

2. Local envenoming (swelling etc.) with bleeding/clotting disturbances, shock or acute kidney injury and neuroparalysis,

3. Local envenoming (swelling etc.) with paralysis.

4. Paralysis with minimal or no local envenoming and

5. Paralysis with dark brown urine and acute kidney injury.4

Polyvalent anti-snake venom has been developed to neutralize the venom of the 'big four poisonous snakes in India'; common cobra (Naja naja), king cobra and common krait (Bungarus caeruleus), Viperidae includes Russell's viper, saw scaled viper and is a lifesaving therapy. However, problems with treatment include hypersensitivity to antivenom and lack of evidence base regarding optimum dosing schedule. 5 Several factors contribute to the increased mortality such as taking treatment from native healers, problems in transport, lack of availability of anti-venom, high cost and lack of hospital-based facilities in rural areas and inadequate knowledge among medical practitioners regarding snake bite management.

The important complications of snakebite include -

1. Shock: One of the most important complications of envenomation is shock due to large amount of peptide and protein content of the venom. Patients may show varying degree of signs of peripheral circulatory failure with or without signs of impending coma, hypotension, renal failure, dehydration, and electrolyte disturbances. ${ }^{1}$

2. Respiratory failure: In cases of severe poisoning by Elapid snakes there can be paralysis of the intercostal muscles and later even the muscles of the diaphragm leading to respiratory failure. Patients may have confusion, drowsiness, stupor or even coma. The respiratory failure is of type-II i.e., there are both arterial hypoxia as well as hypercapnia.

3. Renal failure: This is particularly seen in case of severe envenomation following bites by Vipera russelli. The cause of renal failure is due to haemorrhage into the kidney, ischaemia, resulting from hypotension, disseminated intravascular coagulation and renal vasoconstriction. The renal cortical necrosis is due to the Schwartzman like phenomenon, patients may have a decreased urine output of less than $400 \mathrm{ml} / 24$ hours associated with fluid and electrolyte imbalance. 6

4. Gangrene: Neglected local necrosis can result in gangrene of the limb. So, the wound should be examined frequently for evidence of necrosis. Early signs of necrosis include blistering, blackening or blanching of the skin, loss of sensation and a characteristic smell of putrefaction. There is high risk of secondary infection, so the necrotic tissue should not be allowed to slough spontaneously but should be debrided under local or general anaesthesia as soon as possible. ${ }^{7}$

\section{METHODS}

The current study was a longitudinal study which was conducted at Vivekanand Hospital, Latur. The study population included cases of snakebite admitted to Vivekanand Hospital, Latur during the study period. It included both the rural and urban people by the side of Latur. Other districts nearby Latur are Nanded, Beed, Solapur, Parbhani, Nizamabad, Bidar, and Gulbarga and have a large rural territory. There is vast agricultural land and most people are farmers. So naturally there are much more cases of snake bite each year visiting to the hospital. The study design was that of a longitudinal design as the patients admitted were examined and followed up for a period of 1 month including hospital stay to see for the presence of complications. Total 70 patients with poisonous snakebites, fulfilling the inclusion criteria and who had given written consent and who were admitted to Vivekanand Hospital, Latur during the study period of two years from December 2012 to November 2014 were included in the study.

\section{Inclusion Criteria}

1. All the patients with the definitive history of snake bite presenting to the Vivekanand hospital

2. All the patients with unknown bites with typical fangs mark.

3. All the patients with unknown bites getting improved with ASV treatment.

\section{Exclusion Criteria}

1. All the patients of snake bite below 12 years of age.

2. All the patients having previous history of snake bite in the recent past (1 year).

3. All the patients of snake bite presenting after 7 days.

4. All the patients having pre-existing renal parenchymal disease, blood dyscrasia or neurological disease

5. All the patients not willing to give written informed consent. 


\section{Methodology}

All patients fulfilling the inclusion criteria were approached and the detailed history including history of treatment given before reaching hospital was taken. The detailed general/local and systemic examination was done. The patients were investigated for bleeding time/clotting time/prothrombin time (BT/CT/PT), platelet count, arterial blood gasses, kidney function test, peripheral blood smear, and other relevant investigations as felt essential for the individual patients. Blood sample $(5 \mathrm{ml})$ for above investigations was drawn every 6 hours. Vitals were monitored every half hourly.

Snakebite was identified from modified criteria of Sarangi et al. ${ }^{8}$ by:

1. Fang marks: Lesions resulting from snake bites are, as a rule, two lacerated punctures, about $1.25 \mathrm{cms}$ deep in the case of non-poisonous and about $2.5 \mathrm{~cm}$ deep in the case of poisonous snake bites. An inverted ' $U$ ' shaped or multiple teeth marks indicate non-poisonous snakebite.

2. Identification of snakes living or dead.

3. Description given by the patient/attender about the snake length, thickness, colour, head etc.

4. The development of signs and symptoms of local or systemic envenomation.

The bites were classified as venomous and non-venomous based on clinical features. In venomous bites an attempt was made to determine whether they were bitten by elapidae or viperidae based on the description or examination (when brought) of the offending snake. Also, whenever the patient had or developed unequivocal neuroparalysis or haemotoxic manifestation, they were assigned to elapidae or viperidae respectively.

Treatment with ASV was started in all poisonous cases on arrival at hospital and loading does of 10 vials over a period of 1 hour was given and the dose was repeated at the interval of 6 hours if coagulopathy persists in cases of haemorrhagic and if neurotoxicity persisted in cases of elapidae bites. Neostigmine is also given in cases of neurotoxic poisonous snake bites.

Each patient was followed for a period of 1 month including hospital stay and after discharge and data of the study participants was assessed for development of following complications -

1. ARF (a rise of at least $0.3 \mathrm{mg} / \mathrm{dL}$ or $50 \%$ higher than baseline within a $24-48$ hours period or a reduction in urine output to $0.5 \mathrm{~mL} / \mathrm{kg}$ per hour for longer than 6 hours).

2. DIC (prolongation of PT and/or a PTT; platelet counts $\leq$ $100,000 /$ microL $^{3}$, or a rapid decline in platelet numbers; the presence of schistocytes (fragmented red cells) in the blood smear; and elevated levels of FDP).

3. Shock (sepsis with hypotension (arterial blood pressure < $90 \mathrm{mmHg}$ systolic, or $40 \mathrm{mmHg}$ less than patient's normal blood pressure) for at least 1 hour despite adequate fluid resuscitation; or need for vasopressors to maintain systolic blood pressure $\geq 90 \mathrm{mmHg}$ or mean arterial pressure $\geq 70 \mathrm{mmHg}$. ${ }^{9}$

4. Respiratory paralysis (requiring ventilatory support according to arterial blood gasses and respiratory assessment).
5. Anaphylactic reaction to ASV (urticaria, shaking chills, fever, nausea, vomiting, diarrhoea, abdominal cramps, tachycardia, hypotension, itching, angio-oedema). ${ }^{10}$

\section{Statistical Analysis}

Statistical analysis was done using percentage and appropriate test of significance was applied using the Epi info version 6.1.

\section{RESULTS}

During the study period from December 2012 to November 2014, 91 cases were admitted at the Vivekanand Hospital Latur. Out of these, 21 cases were found to be non-poisonous and remaining 70 were of poisonous snake bites. Following are the observations made in those 70 cases. Majority of patients were below 30 years. The poisonous snake bites are more common in males. The male to female ratio is $2.5: 1$. Poisonous snake bites are mainly seen in rural agricultural labours as $87.1 \%$ of our cases were from rural places, while the rest $12.9 \%$ cases were from urban places.

Poisonous snake bites mostly occur in the farm while working and farmers outnumbered all other occupations for the incidence of snakebites. In our study, $50 \%$ of the cases were of farmers. Though the snake bite did not spare any socio-economic class, the major burden of the disease is on poor man (58.6 \%) followed by middle class (34.3\%). Poisonous snake bites are very rare in upper socio-economic class $(7.1 \%)$. The study shows that maximum number of poisonous snake bites occurred between 12 noon and $6 \mathrm{pm}$ (57.1\%). A substantial high incidence $(28.6 \%)$ of poisonous snake bites were noted from $6 \mathrm{pm}$ to 12 midnight. Overall maximum bites occurred between 12 noon to midnight $(85.7$ $\%)$. Poisonous snake bites were distributed all around the year, except in February (both years) when no bite was reported. Maximum number of cases were noted between May to October (80\%), which coincides with peak farming activity and rainy season. Limbs (97.1\%) are the commonest site for poisonous snake bites. Among the limbs, lower limbs (67.1\%) were commonest site followed by upper limbs (30 $\%)$. Two cases had unusual sites of bite one on right eyelid and another over buttock. Among all poisonous snake bites, majority of cases were due to Viperidae snake bites (52.9\%). Elapidae snakes had bitten $28.5 \%$ cases. In $18.6 \%$ cases, a biting snake could not be identified. Three cases brought dead or alive snakes for identification.

Fright was the common symptom seen in $80 \%$ of patients. Usually developed within minutes of bite and subsided ones the patient received any form of treatment. Local pain was another symptom which was noted in all types of poisonous snakebites, though most common and persistent in viper bites. Pain had its onset between 2 minutes to 2 hours, varied in intensity from mild to severe. Local swelling was noted in $37.1 \%$ patients. It was predominantly a manifestation of viper bites. Patients with mild to moderate swelling were not aware of it. All the patients developed ptosis (100). It was the earliest feature in those cases followed by Ophthalmoplegia (75 \%). Palatal and Pharyngeal palsy (70 \%). Most cases showed the sequential progression from ptosis to respiratory inadequacy. 
Only one patient developed coma. None of the patients had convulsions. Bleeding from the bite site $(73 \%)$ was the commonest manifestation followed by hematuria $948.6 \%$ ), gum bleeding (24.3\%). Ecchymosis and hematoma were also seen in 9 cases $(24.3 \%)$. Though three patients developed hypotension, it was not attributed to cardiotoxicity and none of the patients in this study had cardiotoxic envenomation.
Acute renal failure was noted in $47.6 \% 10$ patients. All of them were viper bites. Among them 12 (44.4\%) patients required haemodialysis, while remaining patients recovered totally on conservative management. Cellulitis was the second most common complication of poisonous snakebites. It was seen in $45.7 \%$ cases.
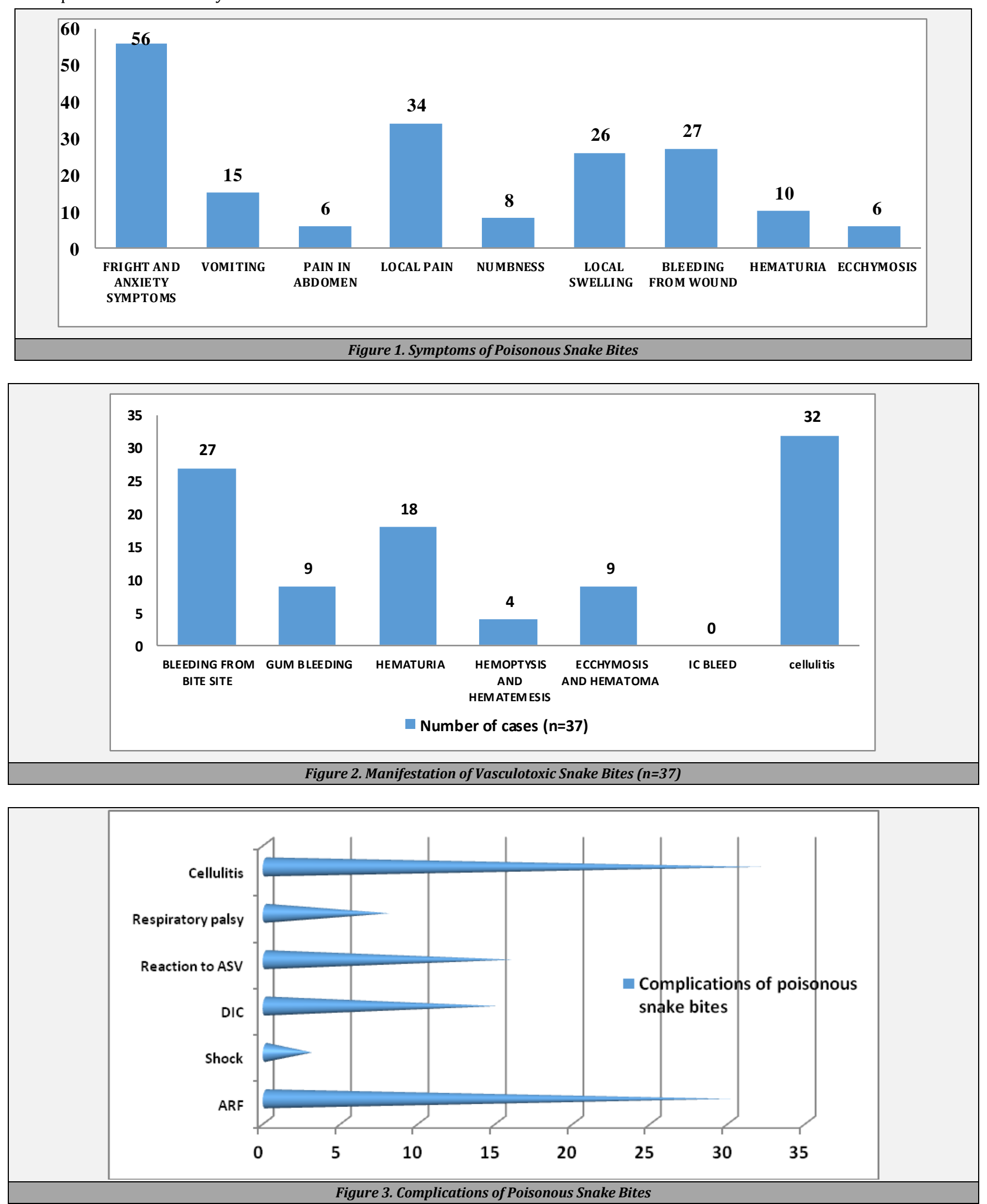


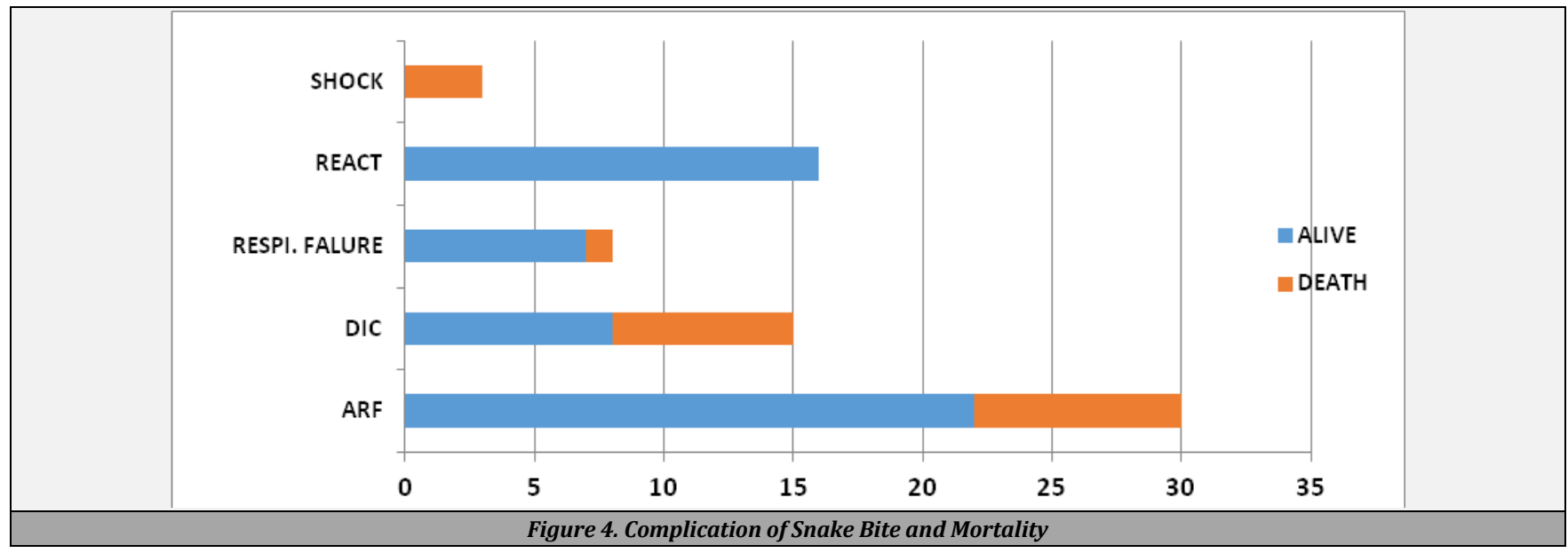

Though respiratory inadequacy was noted in 16 patients, only 8 had respiratory palsy requiring assisted ventilation. Six patients were put on invasive ventilation while other two were managed with non-invasive ventilation (NIV). DIC accounted for the $23.8 \%$ cases and shock was observed in 3 cases ( $4.8 \%$ ). Out of 70 cases studied, 10 patients died during the study period and overall mortality was $4.3 \%$. Table 1 shows the death percentage in each category of complications. Out of which statistically significant values were seen in acute renal failure (26.6\%) and disseminated intravascular coagulation (23.3\%). Both these complications were significantly associated with mortality. Respiratory failure was not associated with significant mortality $(\mathrm{x} 2=$ 1.6). (In other complications, chi-square test was not valid as the number of deaths were less than two). All patients with shock $(100 \%)$ died. The parameters shown in figure 4 were evaluated in terms of outcome (mortality). It was found that haemoglobin less than $9 \mathrm{~g} \%$, total leukocyte count > $11000 / \mu \mathrm{l}$, International normalized ratio (INR) more than 1.5 were statistically significant with mortality.

\section{Analysis of Anti-Snake Venom Treatment}

In our study, we have administered anti- snake venom to all patients as all were poisonous. 65 (arrived to the Vivekanand hospital less than 24 hours from bite and got treatment with anti- snake venom. Unfortunately, 5 patients arrived more than 24 hours from bite and there was no history of treatment with anti- snake venom. Overall, 16 (22.9\%) patients developed reaction in various forms to ASV treatment. 7 out of 65 who received ASV treatment in first 24 hours and 3 out of 5 who had not received ASV treatment in first 24 hours died. As shown in table 18, the dose of antisnake venom in all patients of snake bites was compared with outcome. It was observed that mortality in patients who received ASV more than $200 \mathrm{ml}$ was higher than those who received ASV less than $200 \mathrm{ml}(\mathrm{P}$ value $<0.01)$.

\begin{tabular}{|ccccc|}
\hline Complication & No. of Cases (\%) & Death (\%) Chi-Square test & p Value \\
ARF & $30(42.9)$ & $8(26.6)$ & $\mathrm{x} 2=6.724 ;$ & $\mathrm{P}<0.01$ \\
DIC & $15(21.4)$ & $7(23.3)$ & $\mathrm{x} 2=16.427 ;$ & $\mathrm{P}<0.001$ \\
Respiratory failure & $8(11.4)$ & $2(25)$ & $\mathrm{x} 2=1.6$ & NS \\
Reaction to ASV & $16(22.9)$ & $0(0)$ & NA & NA \\
Shock & $3(4.2)$ & $3(100)$ & NA & NA \\
\hline \multicolumn{4}{r}{ Table 1. Complication of Snake Bite and Mortality } \\
\hline \multicolumn{5}{r}{} \\
\hline
\end{tabular}

\section{DISCUSSION}

Snakebite is a common and a serious problem in a tropical country like India. Epidemics of snake bite has resulted from a sudden increase in snake population density. Snakebite is an occupational disease of farmers, herders and hunters. Invasion of the snake's habitat by large number of people may also be followed by increased incidence of snakebite. In tropical countries where snakebite is a serious problem there are few reliable data. Many patients undergo native treatment for snakebites. Those people reached the hospital late and have increased morbidity compared to the people who received ASV early. It is a prospective study of total number of 70 cases of poisonous snakebites.

In our study, poisonous snakebite was observed in all age groups. The maximum number patients were in the age group 18 - 29 years, they constituted $56.6 \%$ patient's range being 18 to 29 , which is comparable to that of Bhalla G et al. R (56.57 \%). ${ }^{11}$ Maximum numbers of cases were seen in 18 to 39 years (80\%) age group. This is because people belonging to this age group are prone for snake bite because of occupational activities.

The incidence of poisonous snakebite is more common among males shown in our study. Male to female ratio was 2.5 : 1 which was also seen by previous studies like Bhalla $G$ et al. (2:1) ${ }^{11}$ and Majumder D et al. (1.7:1).12 It is obviously due to the increased risk of exposure to the snake bite occupationally.

Snakebite is mainly the disease of the rural population. In the present study, $61(87.1 \%)$ patients were from rural population and $9(12.9 \%)$ from urban population. The findings are consistent with finding of Bhalla G et al. (90.8\% Vs $9.2 \%) .{ }^{11}$

The incidence varies in different regions of India due to various factors, mainly being rainfall, rainy season, pattern of agricultural activity. In our study, high incidence was noted between May to October (83.3\%). This is consistent with findings of Redewad $\mathrm{N}$ et al. $^{13}$ and Punde et al. ${ }^{14}$ In most studies, the highest incidence corresponds to months of rainy season when rainwater compels the snake to come out of their dwellings.

Our study showed that maximum number of bites i.e., $57.1 \%$ occurred between 12 noon to $6 \mathrm{PM}$ which is similar to findings of Rao et al. ( $45 \%)^{15}$ and total $72.7 \%$ bites occurred 
between 12 noon to 12 midnight, which is similar to findings of Sawai et al. ${ }^{16}(64 \%)$. Afternoon bites correspond to peak agricultural activity, while evening bites are combination of activity and poor lighting.

In our study, maximum number of bites occurred on lower extremities (67.14\%). The incidence in our study is similar as observed by Redewad et al.13 (65\%) and Punde et al. (54.3\%). The lower and upper extremities constituted $97.14 \%$ bites.

The haemorrhagic (52.9\%) poisonous snake bites were found more frequently than neurotoxic type (28.5\%). Other studies Nigam et al. ${ }^{17}$ and Sarangi et al. ${ }^{8}$ also reported high incidence of haemorrhagic manifestations. No cardiotoxicity was noted in our study. It is due to the fact that relative prevalence of toxic varieties of snakes could vary in different region of country depending on prevalence and distribution of snakes.

In the present study, bleeding from bite site was most common (73\%) haemorrhagic manifestation, followed by hematuria (48.6\%), gum bleeding (24.3\%) and ecchymosis (24.3\%). Kumar G P et al.18 reported bleeding from bite site in only (64.5\%), followed by hematuria (48.4\%), ecchymosis (32.3\%). Also, Bhalla et al. ${ }^{11}$ noticed hematuria in $42.9 \%$ cases in their studies which is similar to our study.

In our study, ptosis $(100 \%)$ was commonest manifestation of neurotoxic bites and was found in all cases. Finding was consistent with findings of Bhalla et al. ${ }^{11}$ Palatal and pharyngeal palsy was present in $70 \%$ in our study but Bhalla et al. ${ }^{11}$ reported it in only $42 \%$ cases. Ophthalmoplegia was present in $75 \%$ of cases in present study and Bhalla et al. ${ }^{11}$ found it in $85.7 \%$.

\section{Analysis of ASV Treatment}

Five patients did not receive ASV in first 24 hours because of late presentation, while 65 patients were given ASV within first 24 hours. In general, in our study, we have administered anti- snake venom to all patients as all were poisonous, and it ranged between 10 to 40 vials.

A high number of patients developed adverse reactions to ASV therapy (22.9\%). But sever reactions were noted in only $5.88 \%$. Other reactions were all mild to moderate and easily controlled with antihistamine, steroids and IV fluids. No death in the study was attributable to ASV. Our results are comparable to studies by Kumar G P et al.18 (19.4\%) but Gadekar et al. ${ }^{19}$ noticed it in only $6.2 \%$ cases

Mortality rates in other studies varied from $3-11 \%$. Apparently high mortality rate in our study may be due to delay in arriving to the hospital after the snake bite or external factors which increase the chances of mortality are not receiving first aid, unavailability of anti-snake venom at health centres, no transport facilities and lack of public awareness about the urgency and need of treatment.

In the present study, 10 (14.3\%) patients died. Eight were due to viperidae bite and remaining two patients were due to elapidae bite. Two elapidae bite patients expired due to sudden respiratory arrest. Mortality rate was consistent with the finding of Redewad et al.13 (14.8\%). Mostly the patients who developed acute respiratory failure (ARF) $(26.6$ $\%$ ) and DIC (23.3\%) died.

Out of the 10 who died, $4(5.7 \%)$ were females and 6 (8.6 $\%$ ) were males. Thus, out of 50 males, 6 died and out of 20 females, 4 died. Out of 10 who died, 7 (10\%) had bite in lower extremity and 3 (4.9\%) had bite on the upper extremity. Total number of patients bitten on the lower extremity was 47 (67.1\%), out of which 7 died. Total number of bites on the upper extremity was 21 (30\%), out of which 3 died.

\section{CONCLUSIONS}

Snakebite is common in rural setup, in agricultural labourers. Most common victims are males in the age group between 18 - 29 years. Commonest biting time was 12 noon to $6 \mathrm{pm}$. Peak incidence of snakebite was observed in between May to October. Viper bites were more common than elapidae in this study.

In neurotoxic envenomation, ptosis was the commonest and earliest symptom while in hemotoxic envenomation, most common symptoms were bleeding from bite site and hematuria.

The commonest complications were cellulitis, acute renal failure and DIC. Shock and respiratory palsy were also noted in some patients. Maximum mortality was observed in patients who were admitted after 24 hours. Early hospitalization and timely ASV were the corner stone in the treatment of snakebite.

Data sharing statement provided by the authors is available with the full text of this article at jemds.com.

Financial or other competing interests: None.

Disclosure forms provided by the authors are available with the full text of this article at jemds.com.

\section{REFERENCES}

[1] Banerjee RN. Poisonous snakes in India their venoms, symptomatology and treatment of envenomation. In: Abuja MMS, ed. Progress in Clinical Medicine in India. $1^{\text {st }}$ edn. New Delhi: Amold-Heinman Publishers 1978:136-79.

[2] Deoras PJ. Snakes of India. Snakes and how to know them. Govt. of Maharastra: Director of Pubilicity 1959.

[3] Mohapatra B, Warrell DA, Suraweera W, et al. Snakebite mortality in India: a nationally representative mortality survey. PLoS Negl Trop Dis 2011;5(4):e1018.

[4] WHO. Guidelines for the clinical management of snake bites in South-East Asian region. South East Asia 2005.

[5] Warrell DA. Snake bite: a neglected problem in twentyfirst century India. Natl Med J India 2011;24(6):321-7.

[6] Merchant MR, Khanna UB, Almeida AF, et al. Clinicopathological study following viperine snake bite. J Assoc Physicians India 1989;37(7):430-3.

[7] Raid HA. Venomous Animals and their Venoms. In: Bucheni W, Buckley E, Deulofeu V, eds. Vol. 1. London, New York: Academic Press 1963:611-41.

[8] Sarangi A, Jena I, Sahoo H, et al. A profile of snake bite poisoning with special reference to hematological, renal, rernological and electrocardiographic abnormalities. J Assoc Physicians India 1977;25(8):555-60.

[9] Longo DL, Kasper DL, Jameson JL, et al. Harrison's principles of Internal Medicine. 18 ${ }^{\text {th }}$ edn. USA: McGrawHill Companies 2012. 
[10] Chippaux JP. Snake-bites: appraisal of the global situation. Bull World Health Organ 1998;76(5):515-24.

[11] Bhalla G, Mhaskar D, Agarwal A, et al. A study of clinical profile of snake bite at a tertiary care centre. Toxicol Int 2014;21(2):203-8.

[12] Majumder D, Sinha A, Bhattacharya SK, et al. Epidemiological profile of snake bite in south 24 parganas district of West Bengal with focus on underreporting of snake bite deaths. Indian Journal of Public Health 2014;58(1):17-21.

[13] Redewad N, Bhaisare SD, Bansod YV, et al. Management and outcome study of snake bite cases in central India. Sch J App Med Sci 2014;2(1D):435-41.

[14] Singh S, Singh G. Snake bite: Indian guidelines and protocol. Medicine Update 2013;24:424-6.
[15] Rao CP, Shivappa P, Mothi VR, et al. Fatal snake bitessociodemography, latency pattern of injuries. J Occup Med Toxicl 2013;8(1):7.

[16] Sawai Y, Honma M. Snake bites in India. In: Toxicon. Vol. 7. Oxford, England: Pergamon-Elsevier Science Ltd 1975:1-16.

[17] Nigam P, Tandon VK, Kumar R, et al. Snake bite--a clinical study. Indian J Med Sci 1973;27(9):697-704.

[18] Monteiro FN, Kanchan T, Bhagavath P, et al. Clinicoepidemiological features of viper bite envenomation: a study from Manipal, South India. Singapore Med J 2012;53(3):203-7.

[19] Wanje SD, Gadekar RD. Clinical profile of snake bite cases in Marathwada, India. Indian Journal of Fundamental and Applied Life Sciences 2011;1(4):93-9. 